\title{
Contribution of Women in Fisheries and Fishery Related Activities in Ponnalai, Jaffna, Sri Lanka
}

K. Nilakshana*, P. Shobiya, J.G.B. Dhanushka Dilini, N. Ragavan, K. Sivashanthini and S.Sutharshiny.

Department of Fisheries, Faculty of Science, University of Jaffna, Sri Lanka.

*Email: nilakshana81@gmail.com

Abstract -Women's involvement in fisheries seems to be largely invisible and unacknowledged in Jaffna Peninsula. Thus, the present study was conducted in Ponnalai village to determine the active participation of women in fisheries, analyse their socioeconomic status and suggest appropriate measures to improve their livelihood. Data were collected using a structured questionnaire and through interviews from October to December 2018. Randomly selected, 25 women fisher folks were interviewed and collected data were subjected to descriptive statistical analysis. In the study area, women were primarily involved in hand picking of shrimps and crabs. Results revealed that $100 \%$ of responders were Hindus and were from traditional fishing families. It was found that $72 \%$ of women were above 50 years in age. The educational status of fishers showed that $80 \%$ were illiterate. The fisheries sector is characterized with the participation of married and widowed women $(64 \%)$. Number of children per women fisher folk was 7 - 9 (52\%). The average monthly fish production varied between $130 \mathrm{~kg}$ to $312 \mathrm{~kg}(60 \%)$ and monthly income varied from Rs.7, 800 to Rs.13, 000. It was apparent that the socio-economic status of women fishers in the study area was poor. Lack of government support, poor literacy rate and low income were the major identified constraints faced by the women fisher folk of this village. Therefore, support from governmental or non-governmental organizations by providing subsidies, loans and technological assistance are essential to improve the livelihood and their socio-economic status.

Keywords - Fisherwomen, Hand fishing, Livelihood, Shrimp, Socio - economics

\section{INTRODUCTION}

In Sri Lanka, women consist of $50.7 \%$ of the total population (10.7 million) and $35.9 \%$ of the labour force ( 8.6 million) in 2019 (Department of Census and Statistics, 2019). Women labour force has significantly contributed to the Sri Lankan economy and their contribution was higher in the services industry $(47.2 \%)$ and lowest for the industrial sector (26.3\%) (Department of Census and Statistics, 2019). $26.5 \%$ of the women labour force were employed in the agricultural sector including fisheries (Department of Census and Statistics, 2019). Fisheries is one of the major economic sectors in Sri Lanka, which significantly contributes (1.2\% of GDP) to the national economy. The sector provided 0.5 million employment opportunities in 2018, and the labour force in marine capture fishing activities is dominated by the men (Department of Census and Statistics, 2019). Most of the women in the fishing community are involved in sorting the harvest from the nets, fish processing, retail fish marketing and gutting of fish in the markets (Bavinck, 1984; Stirrat, 1988).

Women's involvement in the coastal fishery is especially to lessen poverty and secure their food and nourishment (Olufayo, 2012). In Jaffna, most of the women in the fishing community support the fishing activities by pre and postharvest from the nets, fish processing, retail fish marketing and gutting of fish in the markets (Bavinck, 1984; Stirrat, 1988). Similar to other parts of the country also few of them are actively involved in the marine fish capture activities by owning fishing boats and fishing operation licenses. These women's participation in fishing activities are not enumerated as a source of employment. The women commitment in fisheries has long been accepted, but neither recognized nor appreciated as men's involvement (Cliffe \& Akinrotimi, 2013). The invisibility of women's participation means absence of institutional recognition, exclusion from the decision-making processes, values and cultures, laws and the state's priority to ensure gender equity (Siason, et al, 2002). Meanwhile, data of full-time fishers of the Sri Lankan marine fishing sector are not distinguished by gender, leading to policies targeted exclusively at men. Hence, it is important to materialize the current status of fisher women and their role in fisheries in Jaffna. Therefore, the present study was conducted in Ponnalai fishing village, in order to determine the active participation of women in the fisheries, analyse their socio-economic status and suggest appropriate measures to enhance their livelihood.

\section{MATERIALS AND METHODOLOGY}

The present study was carried out from October 2018 to December 2018at Ponnalai fishing village (Fig. 1), which is located in Jaffna district, Northern Province of Sri Lanka, which lies between $9.7498^{\circ} \mathrm{N}$ and $79.9186^{\circ} \mathrm{E}$. This fishing village belongs to Chankanai Divisional Secretariat division and Ponnalai J/170 Grama Seva division. The fishing ground is ideal for the coastal fishing activities because of the promising climatic conditions that ensure the year-round fishing.

Primary and secondary data collection was implemented during the field survey in order to gather data regarding role of fisher women in Ponnalai lagoon. Primary data were obtained at the lagoon and Sri Kannan Fisheries Co-operative 

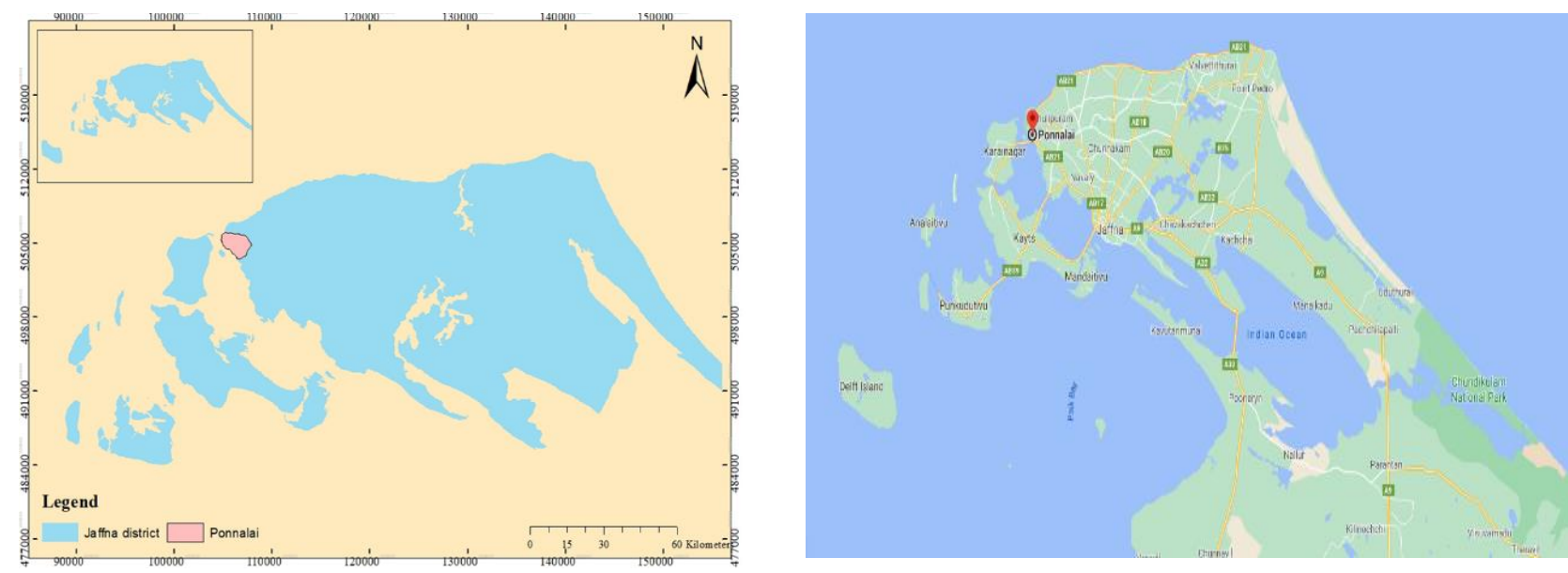

Fig. 1: Location map of Ponnalai fishing village.

Society. Structured questionnaires, direct observations and group discussions were used to collect data from 25 fisherwomen (of the 57 full-time fisher women), who were involved in fishing at Ponnalai lagoon. The socio-economic aspects studied were age, religion, marital status, education, type of fishing family, average catch per month and average income per month. SWOT analysis was performed to know the threats and challenges faced by the fisherwomen in their fishing and fishery related activities. Secondary data were collected from journals, books, reliable websites Grama Niladari (GN) office and the Fisheries Co-operative Society to get additional information related to livelihood status of fisher women.

\section{RESULTS AND DISCUSSION}

Ponnalai is one of the fishing villages in Chulipuram Fisheries Inspector (FI) division, Jaffna. There are about 250 full-time fishers, who are involved in the lagoon fishing activities. Of these, 57 of them are women, where about $23 \%$ of the lagoon fisher population are in Ponnalai region. All of them are Sri Lankan Tamils and Hindus. Descriptive statistical analysis was done with the aid of Microsoft Excel@ analytical tool to obtain the percentage value of selected socio-economic profiles.

\section{A. Age structure and marital status}

The age of fisherwomen interviewed was ranged from 37 to 68 years. The results showed that highest women participation in active fishing was recorded in the age above 50, which was about $72 \%$ and lowest from $30-50$ years age group. According to the survey, majority (64\%) of the fisherwomen were widowed and about $36 \%$ were married (Fig. 2).

Female-headed families during the post-war period are characteristic features in the rural communities in this region (Jeyasankar \& Ganhewa, 2018). Widowed households reflect that the fisherwomen are needed need to be actively involved in fisheries in order to secure their daily living, food and income (Nwabeze, et al, 2010).

\section{B. Literacy rate of fisher women}

Around $80 \%$ of the women in the study group was found to be illiterate and $20 \%$ had primary education (Fig. 3). Majority of the women from the Ponnalai region are descendants from traditional fishing families and had started to go to sea at their age of about twelve. Their poor socio-economic conditions pushed them towards fishing in order to stabilize family income. These may be the reasons for refraining from accomplishment of good education at their young ages. It can be compared with similar studies conducted around Jaffna peninsula, where the literacy rate of fisherwomen was found to be lower than the fishermen (Ragavan, et al, 2017; Tharmine, et al, 2018; Shobiya, et al, 2019).
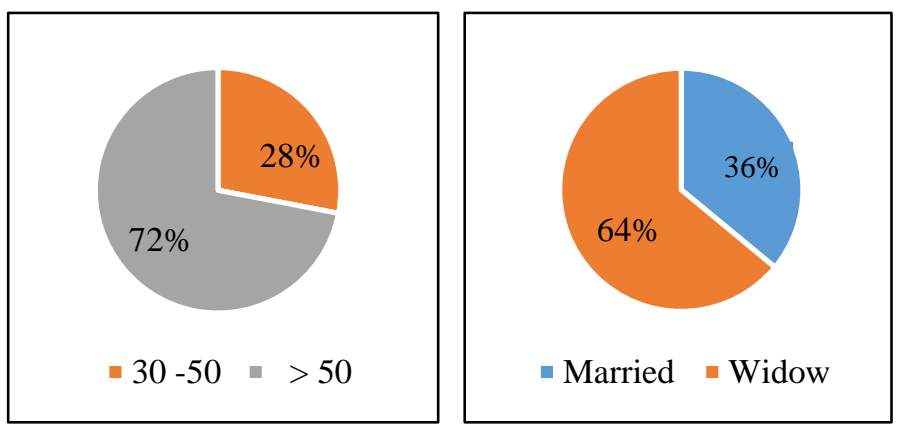

Fig. 2: Age composition of the fisherwomen (Left side) and their marital status (Right side) in Ponnalai in 2018.

\section{Number of children and their literacy rates}

Fifty two percent of the fisher families studied had number of children as high as 7-9. Small family sizes with 2-3 children formed only $12 \%$ and $36 \%$ of families were with $4-6$ children (Figure 4). Due to their early marriages and high number of children in the families, they are compelled to engage in the fishing activities to sustain by their families even after their marriage. 
In addition, being female-headed families, the family income was solely dependent on elderly females for their livelihood. The majority of the children has completed their secondary education $(80 \%)$ and $8 \%$ had completed their tertiary education (Fig. 4). In the present situation, children are keen to attend school. This is because a strong belief had been embedded to them that a good employment can be secured through better education, which in turn will be useful for them to earn more money and occupy a stable position in the society. It is evident that the literacy rate of younger generation had shown a great leap in the recent years.

\section{Fishing methods}

The fisherwomen directly depend on lagoon fishing activity with the manual picking method by targeting shrimps and crabs. They go for fishing activities walking in the lagoon up to the depth of their hip and manually pick the target organisms in that region. They use Karappu (basket) to store their harvest in the lagoon region, which is tied in their hip. These fishing activities are carried out from early morning from 5.00 am to 9.00 a.m. Average catch obtained per day is around 2 to $4 \mathrm{~kg}$. The amount of harvest depends on the precipitation and tidal changes. Higher catches of crabs were collected during May, while shrimps during March. Resources are getting scarce, and as such, number of active fisherwomen showed a severe decline.

The catch is primarily used for home consumption and the surplus is sold in the nearby auction market. As all the fisherwomen are Hindus, they tend to follow some rules and regulations related to fishing activities to a great extent. They were engaged in fishing activities throughout the year and six days per week except on Fridays.
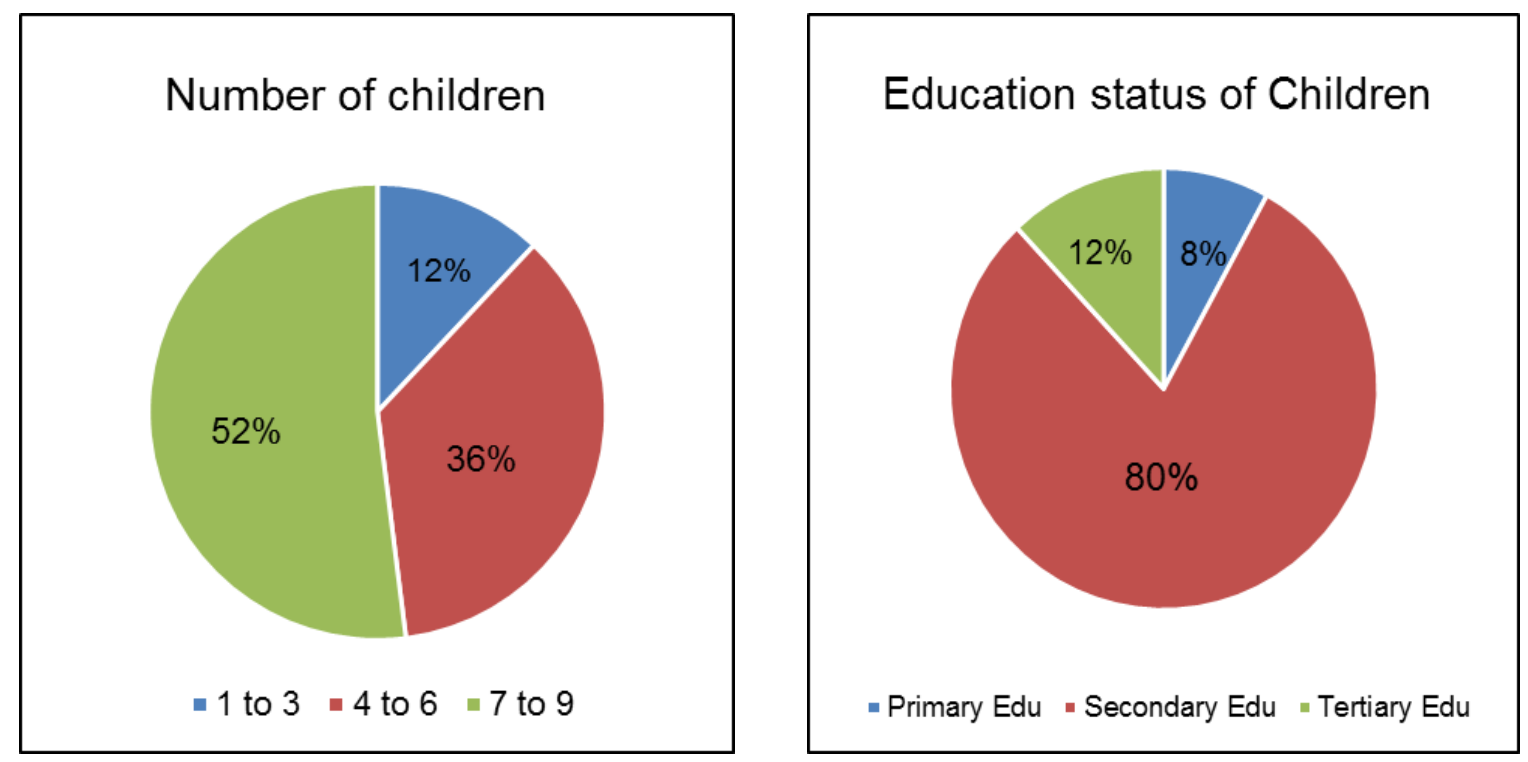

Fig. 4: Number of children of the fisherwomen (Left side) and their Educational status (Right side) in Ponnalai in 2018

\section{E. Income}

The average monthly income of fisher women ranged from Rs.7, 800 to Rs.13,000 (Fig. 5). During the rainy seasons and uneven climatic conditions that are not favourable for fishing, some fisher women shift their primary occupation to other fishery-related activities. Such as selling fish in the market and casual labour for daily wages. Due to their poor economic conditions, they were unable to invest in the fishing activities with advanced fishing techniques. This had been a great obstacle for them to expand and diversify their fishing activities. Therefore, those fisher women, who involved actively in fishing, picked shrimps and crabs manually around the coast $(<100 \mathrm{~m})$. As they were adopted to manual fishing methods, fishing effort is greatly limited.

\section{Literacy rate of fisherwomen}

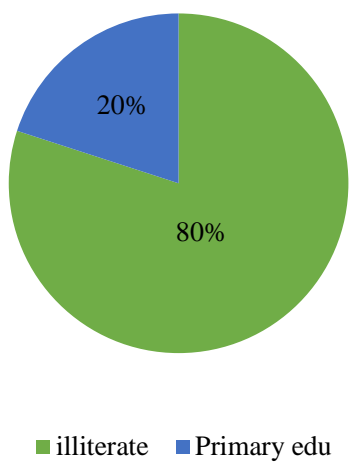

Fig. 3: Education status of the fisher women in Ponnalai in 2018

\section{Education status of Children}

Primary Edu - Secondary Edu - Tertiary Edu 

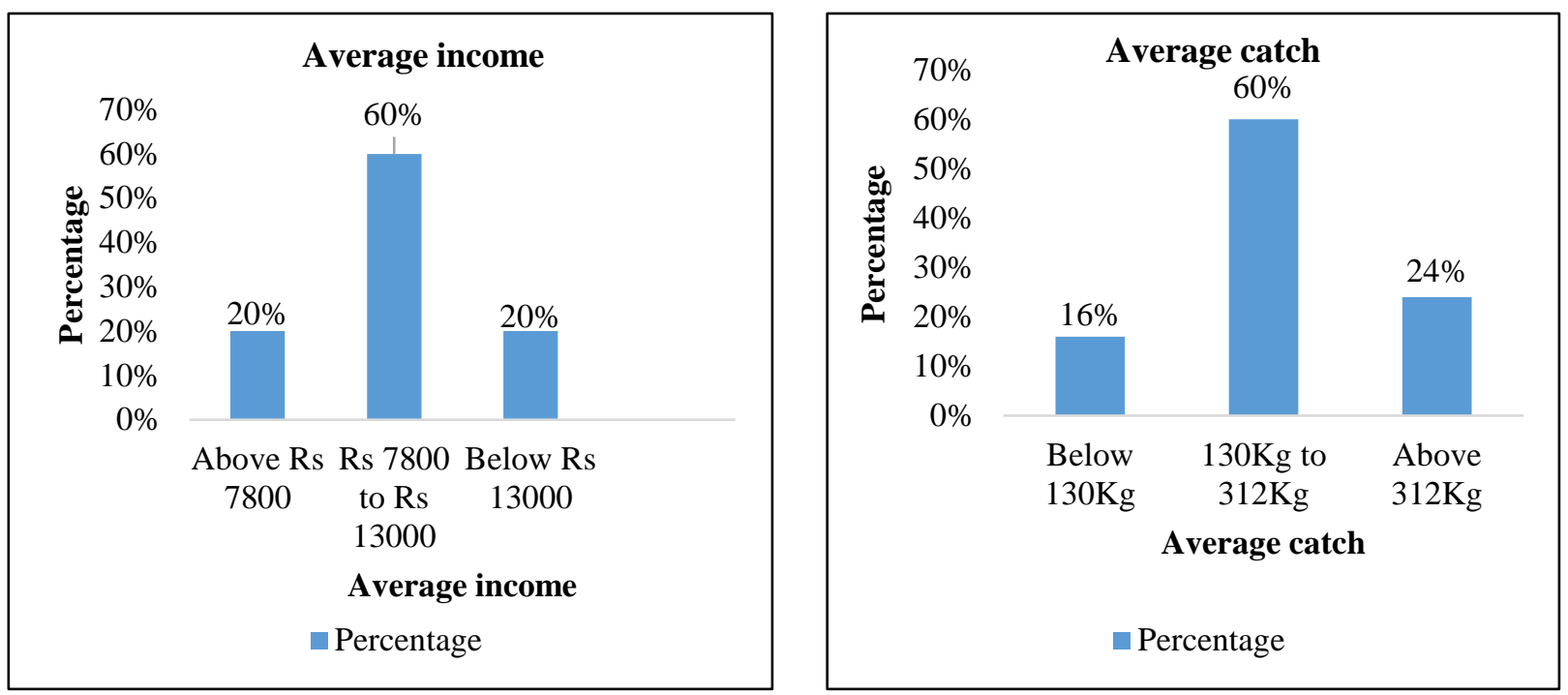

Fig. 5: Average catch and their income per month of women fisher folk in Ponnalai, 2018.

\section{F. SWOT Analysis}

The following strengths, opportunities, weaknesses and threats were identified through the present study.

\begin{tabular}{|l|l|}
\hline Strengths & \multicolumn{1}{|c|}{ Opportunities } \\
Women's participation & $\begin{array}{l}|c| \\
\text { Existing policies and } \\
\text { in coastal fisheries. }\end{array}$ \\
Potential food security. & $\begin{array}{l}\text { Increasing environmental } \\
\text { awareness. } \\
\text { Wild collection of aquatic } \\
\text { organisms }\end{array}$ \\
\hline
\end{tabular}

\begin{tabular}{|l|l|}
\hline $\begin{array}{l}\text { Weaknesses } \\
\text { Poor post-harvest }\end{array}$ & \multicolumn{1}{|c|}{ Threats } \\
technology. & $\begin{array}{l}\text { Uncontrolled harvesting. } \\
\text { Reduction of density and } \\
\text { diversity of shrimps and crabs. }\end{array}$ \\
Lack of modern \\
technology. \\
$\begin{array}{l}\text { Lack of infrastructure } \\
\text { and skilled man-power. }\end{array}$ \\
$\begin{array}{l}\text { Lack of organizational } \\
\text { support. }\end{array}$ \\
\hline
\end{tabular}

In the lagoon, deep catching methods are impossible. Therefore, both men and women have to involve in shore line harvesting methods. However, the problem is that almost all the women use only hand-picking, while males are using stake net and Raalkoodu, which always provides a higher harvest resulting in higher earnings by men. It may affect financially for women headed families. On the other hand, the harvesting method of hand picking used mostly by women is environmentally friendly, since they selectively catch only the matured and optimum size fishes, shrimps and crabs. But in the case of men, they catch all the sizes of fishes including juveniles, which may finally lead to overfishing.

When these two groups are compared, at present men may earn more than women. But, in the future, both parties may face problems in harvesting mature organisms, due to these irrational harvesting methods, where men are using nets and may decrease the survival rate, which may lead to a decrease in earnings of both parties.

The support of governmental and non-governmental organization may enhance the livelihood and empowerment of fisher women by providing suitable fishing gear and crafts, which will lead to higher yield. For example, boats are issued at subsidized prices by the Ministry of Fisheries. All women are well experienced in fishing activity. Therefore, their knowledge should be improved by giving correct instructions about harvesting and regular monitoring of culture processes like sea cucumber culture and seaweed culture, as well as dry fish production. These activities can be easily conducted in seashore areas and definitely improve the quality of their life since their involvement is higher in the said activities. 


\section{CONCLUSION}

The results from the present survey revealed that around $23 \%$ of full-time fishers in the Ponnalai were fisherwomen and majority of them were older (72\%) and widows (64\%). Most of the fisherwomen were illiterate and $80 \%$ of their children had completed their secondary education. These fisherwomen target shrimps and crabs by manual picking in the lagoon by walking inside shallow depths without any fishing crafts. Their monthly income ranged from Rs.7, 800 to 13,000 , while $60 \%$ of them received an average income. However, they were under the poverty line.

To enhance the livelihood and empowerment of fisherwomen the following solutions are recommended:

- Promote livestock farming;

- Introduce seaweed culture;

- Training for fish processing/ dry fish processing.

\section{ACKNOWLEDGEMENT}

Our thanks are due to the fisherwomen of Ponnalai fishing village, who gave support and information to successfully complete the research study.

\section{REFERENCES}

Bavinck, M. (1984). Small fry: The economy of petty fishermen in Northern Sri Lanka.

Cliffe, P. T., and O. A. Akinrotimi (2013). "The role of women in fishery activities in some coastal communities of Rivers State, Nigeria." 397-401.

Jeyasankar, V., and Ganhewa, S. (2018). Colombo: International Centre for Ethnic Studies. Making Ends Meet: Women's Livelihoods in Post-war Sri Lanka.

Nwabeze, G. O., Ifejika, P. I., Tafida, A. A., Ayanda, J. O., Erie, A. P., and Belonwu, N. E. (2010). Gender and fisheries of lake Kainji, Nigeria: A review 590-595.

Olufayo, M. O. (2012). The gender roles of women in aquaculture and food security in Nigeria. Retrieved February, 3, 2016.

Ragavan, N., Sivashanthini, K., and Sutharshiny, S. (2017). Socio-economics status of fishermen of Allaipiddy village, Jaffna. Vingnanam Journal of Science, 12(1-2): $42-48$.

Shobiya, P., Sivashanthini, K., Sutharshiny, S., and Gunaalan, K. (2019). Impacts of the Thondaimanaru Barrage Construction on Socio-Economic Status of Fishing Communities in Thondaimanaru Lagoon, Jaffna, Sri Lanka. Vingnanam Journal of Science, 14(1): 27 - 32.
Siason, I., Tech, E., Matics, K. I., Choo, P. S., Shariff, M., Heruwati, E. S., and Sunderarajan, M. (2002). Women in fisheries in Asia.

Sri Lanka Labour force statistics (2019). Department of Census and Statistics, Ministry of Economic Reforms and Public Distribution.

Stirrat, R. L. (1988). Hindustan Publishing Corporation. On the beach: fishermen, fishwives and fish traders in postcolonial Lanka.

Tharmine, A., Sivashanthini, K., and Edrisinghe, U. (2018). Socio economic status of crab fishers and marketers in Navanthurai fishing village in Jaffna estuary, Sri Lanka. Tropical Agricultural Research Vol. 29 (3): 322 - 329. 